\title{
BURNS
}

\author{
J. P. Bull, M.D.
}

Medical Research Council Industrial Injuries and Burns Research Unit, Birmingham Accident Hospital

\section{Incidence and Etiology}

IN England and Wales there are annually between 700 and 800 deaths from burns and scalds. The majority of these fatal accidents occur in the home, and many of the victims are old ladies. Deaths among children are also disproportionately high for the population at risk. Industrial burns account for about 100 deaths per year, almost all of these among males of working age. For every fatal burn there are about 20 other non-fatal injuries severe enough to require in-patient hospital treatment: a high proportion of these are injuries to children, their most serious burns being caused by clothing catching alight, often from open fires. Hot fluids used in cooking and washing are common causes of scalds. Elderly women also often burn themselves from careless use of open fires and naked lights; quite often other infirmities predispose them to such injuries, for example attacks of unconsciousness or giddiness. At all ages epilepsy predisposes to burns and usually the injuries are particularly deep and disfiguring owing to prolonged exposure to the heat source. Most of the serious domestic burns would be prevented if clothing of lower flammability were used, e.g., to B.S. 3120 or 3121. Another valuable precaution would be the universal guarding of all types of open fire, especially when children and old people are in the room (Bull, r96r).

The industrial burns are due to a variety of contacts with hot materials or chemicals; among metal workers burns from molten metal are fairly common and are characteristically of small area but usually affect the full thickness of the skin because of the intense heat of the molten material. Chemical burns are caused by strong acids and alkalis and by phosphorus, metallic sodium and other articles which generate heat on exposure to air or water. Prolonged exposure to a number of relatively innocuous agents can also cause burns, for instance if persons are trapped under vehicles after a road crash, it is possible for them to suffer extensive chemical burns from spilled petrol.

\section{Pathology}

The common feature in the causation of all burns is an adequately prolonged exposure to the noxious agent. Typically the injury is due to heat, and curves giving the minimum times and temperatures for different exposures to produce different degrees of burning can be calculated (Moritz \& Henriques, 1947; Sevitt, 1949). summary of such findings is shown in Fig. I.

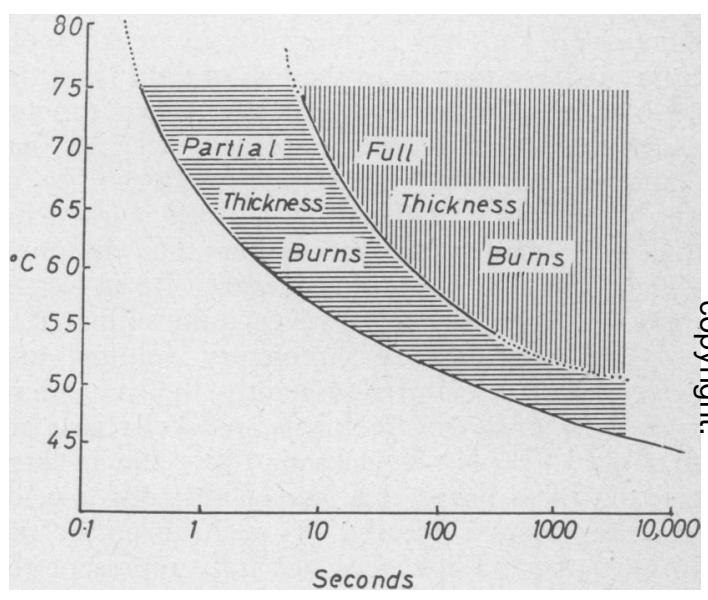

Fig. 1.- Temperature and duration of exposure sufficient to cause burns in areas of thin skin.

Histological examination of burned skin shows destruction of tissues of all types down to a level where a zone of partially viable tissue separates the necrotic area from normal tissue. The most important clinical distinction depends upon the amount of living epithelial tissue remaining; if the burn is superficial, only the outer layers of the epidermis are damaged, and healing occurs within a few days by replacement of the damaged tissue from the surviving stratum germinativum. In deeper burns this layer itself may be damaged, but the epithelium which lines the sweat ducts and the hair follicles may survive and provide complete healing in two or three weeks. These injuries are commonly called 'partial thickness burns'. More severe injuries which destroy all epithelial elements and therefore remove all prospect of sound spontaneous healing are termed 'whole thickness burns'. At the margins 
of such burns there will be a possibility of germinal cells migrating into the damaged tissue and producing some healing, but if the area is more than a few centimetres in diameter, permanent satisfactory healing is unlikely unless the area is grafted with skin from elsewhere.

The injury causes an inflammatory dilatation of the local capillary bed and a great increase of its permeability. This may lead to local collections of fluid in blisters; more general spread of the fluid results in local œdema. If the surface of a burn or the blister is removed the fluid will exude freely. This fluid contains plasma protein, with some of all the usual protein fractions but with a predominance of the smaller molecules such as albumin. The total concentration of protein in blister fluid is often about three-quarters that of the plasma from which it is derived.

There is still dispute as to how important increases in capillary permeability in areas remote from the burn may be in the loss of fluid from the circulation. Arturson (196r) in animal experiments using dextran of different molecular weights, has demonstrated some increase in permeability in uninjured limbs, though this is most marked for molecular sizes somewhat smaller than albumin, which are scarce in normal plasma. Local loss of fluid in a large burn is, however, quite sufficient to cause marked loss of circulatory volume, and since plasma is lost predominantly, the hæmatocrit rises. In more severe burns, red cells also are destroyed (Topley \& Jackson, 1957) and in large full thickness burns this loss of red cells may be very important clinically. In such burns the rise in hæmatocrit value does not fully represent the loss of circulatory volume since the 'marker' red cells also disappear.

Probably mainly as a result of the disturbance of circulatory volume and the associated vasoconstriction, damage to organs such as the kidney and liver is common in severe burns. Sevitt (1956) has described three types of kidney damage: one a localized necrosis usually of no great clinical consequence, another a combined glomerular and tubular lesion similar to that commonly known as lower nephron nephrosis, and a third type of damage of the proximal tubules and found in old persons. In fatal burns it is common to find vascular engorgement and petechial hæmorrhages in the alimentary wall and there may be a duodenal ulcer (Curling's ulcer). Other pathological features in burns are related more to the treatment than to the original lesion. Pulmonary œdema can result from excessive fluid therapy, though there is often in these cases predisposing disease or injury to the cardiorespiratory system. If very large quantities of pooled plasma are given to Group A patients, a secondary hæmolysis due to the accumulation of $\frac{\varrho}{z}$ anti-A antibodies from the pooled plasma may result (Topley, Bull, Maycock, Mourant and $\mathcal{\complement}$ Parkin, 1963).

Infection is the most important complication $\stackrel{\vec{\rho}}{\vec{a}}$ of burns. The damaged area forms an excellento medium for the growth of many pathogenico organisms. Common invaders are Staphylococcus $\overline{\bar{D}}$. aureus and Pseudomonas pyocyanea and other $\mathbb{Q}$ coliforms. Less common, but of great clinicalo importance are infections with hæmolytic strep- tococci (Lowbury, I960). Such infections. interfere with the normal healing processes, may $\vec{\omega}$ prevent the 'take' of grafts and give rise to toxæmiao and not uncommonly fatal septicæmia. Infectivę pulmonary complications are also common and 3 . are often caused by the same organisms as arew present on the burn.

\section{Treatment}

It follows from the pathology of the burn $\vec{v}$ lesion that the main problems in treatment are prevention of shock by suitable replacement of fluid and prevention of infection. If all the living elements of the epidermis are destroyed there is the further problem of supplying cells from? elsewhere to resurface the damaged area.

\section{Fluid Replacement}

The loss of fluid caused by burns of moder extent, say $5 \%$ of the surface area of the body, normally within the body's adaptive capacity so that, though there is temporary reduction of circulatory volume, this is soon replaced fromo reserves of fluid and protein and the blood pressure remains within normal limits. More $\vec{F}$ severe burns (more than $15 \%$ surface area in 3 adults, or $10 \%$ in children) cause sufficient disturbance of body fluids to require specific therapy. Since the loss of fluid is spread overo several hours, the patient when first seen may not. be in a state of clinical shock, and it is important to recognize at this stage the patients who are later likely to be at hazard. An approximate estimate of surface area based on the 'Rule of Nines' (Wallace, I95I) provides a useful guide. It can easily be remembered that the surface area of each upper limb and of the head and neck are approximately $9 \%$; each lower limb, the front and the back of the trunk are each $2 \times 9 \%$. Moren accurate estimates of area can be made by using a body area chart.

Since fluid loss is predominantly of plasma reconstituted dried plasma is a rational form of therapy. It should be given by continuous intravenous drip and oral fluids should also be provided to supply normal losses by respiration urine, etc. A good guide to the rate of plasma 
infusion is the response of the patient's hæmatocrit. The hæmatocrit on admission commonly shows some degree of hæmoconcentration corresponding to loss of plasma between infliction of injury and admission. Plasma should be given to correct this towards a normal value and the degree of success achieved can be checked by hourly repetition of the hæmatocrit determination. When the hæmatocrit has returned to the normal value (for the age and sex of the patient) the circulatory volume will be approximately normal and this can be sustained by continuing the plasma infusion at a slower rate. Treated by this regime, burns up to about $30 \%$ surface area will have received almost all their colloid infusion within 24 hours and half of this total amount will commonly have been given in the first eight hours. Burns larger than $30 \%$ often give more difficulty and may require plasma infusion up to 48 hours. These same patients often suffer appreciable losses of red cells and this makes the use of the hæmatocrit as an index of blood volume less reliable. However, its use will result in under- rather than overinfusion. In such cases a blood volume estimate, preferably using ${ }^{51} \mathrm{Cr}$-labelled red cells, is often helpful (Davies, I960).

Urinary volume can provide another guide to adequacy of fluid replacement. If output remains normal or high, replacement is usually sufficient. Oliguria for a few hours however, is common during the first 12 hours, but if it persists it should arouse concern. At this stage it is useful to test urinary concentration by specific gravity or preferably by determination of the freezing point. If the small volume of urine is well concentrated, kidney function will almost certainly recover completely, but if the output is both of low volume and low concentration (e.g., osmolarity of 300 to $400 \mathrm{~m}$ Osm/1.) then serious tubular damage is likely. A fixed low concentration can also occur with apparently normal volume, and this leads to uræmia without oliguria. Urine output is therefore inadequate as a guide by itself.

The fact that many burns seem to require an amount of infusion proportional to the area of burn has been the basis of a number of formula intended to provide a guide for fluid therapy. In 1942 Harkins suggested that about I litre of plasma should be allowed per $10 \%$ of burn in the first 48 hours, and to this was added a further similar quantity of saline. Cope and Moore (1947) tested this formula using the newly developed techniques of plasma volume and extracellular fluid estimation. They found that many burns of $30 \%$ surface area or more caused an expansion of ECF of about $50 \%$ and that this did not vary much with the size of burn. They therefore proposed that in 48 hours all such burns should have $10 \%$ of the body weight of a two-thirds mixture of plasma with one-third saline, and to this should be added an amount varying with the size of the burn to supply free exudate. There was a further allowance of water for renal excretion and insensible loss. Cope found that some patients who did badly had a large expansion of ECF and he considered that it was probably safer not to allow the ECF to expand more than about $50 \%$, hence his maximum allowance of $10 \%$ body weight to supply œdema. The cases he quotes had pulmonary complications either from the initial burn or subsequent broncho-pneumonia, and in any case were poor risks on any form of therapy.

The next major study was by Everett Evans' team in Richmond (Evans, Purnell, Robinett, Batchelor and Martin, 1952). A tęchnique was developed for producing 20 to $30 \%$ burns in dogs, and plasma and red cell losses were measured by labelling techniques. By 6 hours the maximum plasma loss had occurred and this amounted to about I $\mathrm{ml} . / \%$ burn $/ \mathrm{kg}$. body weight. A similar formula was used for treating patients: $\mathrm{Iml} . / \% / \mathrm{kg}$. colloid was given in 24 hours with the same quantity of saline. To avoid pulmonary œdema the upper limit was placed at a $50 \%$ burn and good clinical results were reported in 68 patients. In the meantime another variant on the N.R.C. formula had been proposed by Wallace (195I): this accepted $75 \mathrm{ml}$. of colloid + saline $/ \%$ burn in the first 24 hours, and gave a table for reducing the amounts at various ages, calculated on proportionality with body weight. The Wallace formula, however, limited therapy to larger burns so that total colloid and saline administered in 48 hours should not exceed 10\% body weight. This ignores loss of exudate and might seem over cautious since Evans, who was also concerned about pulmonary œdema, found that almost twice the maximum allowed by the Wallace formula did not lead to this trouble.

In Fig. 2 the amounts of total colloid + saline solution recommended by the various formulæ are calculated for a range of sizes of burns in an adult of $70 \mathrm{~kg}$. over the first 24 hours. It will be seen that the Harkins, Evans and Wallace formula are similar up to a burn size of $30 \%$ and that Harkins and Evans would continue to recommend similar quantities to about $50 \%$, and at this point the Cope formula is similar. As mentioned above, several studies had suggested that the Harkins formula provided dangerously large amounts of saline above this size of burn and both the Cope and Evans formula give only slighter increases beyond this size of burn. Our experience in Birmingham using continuous control by hæmatocrit, urinary volume and clinical state 


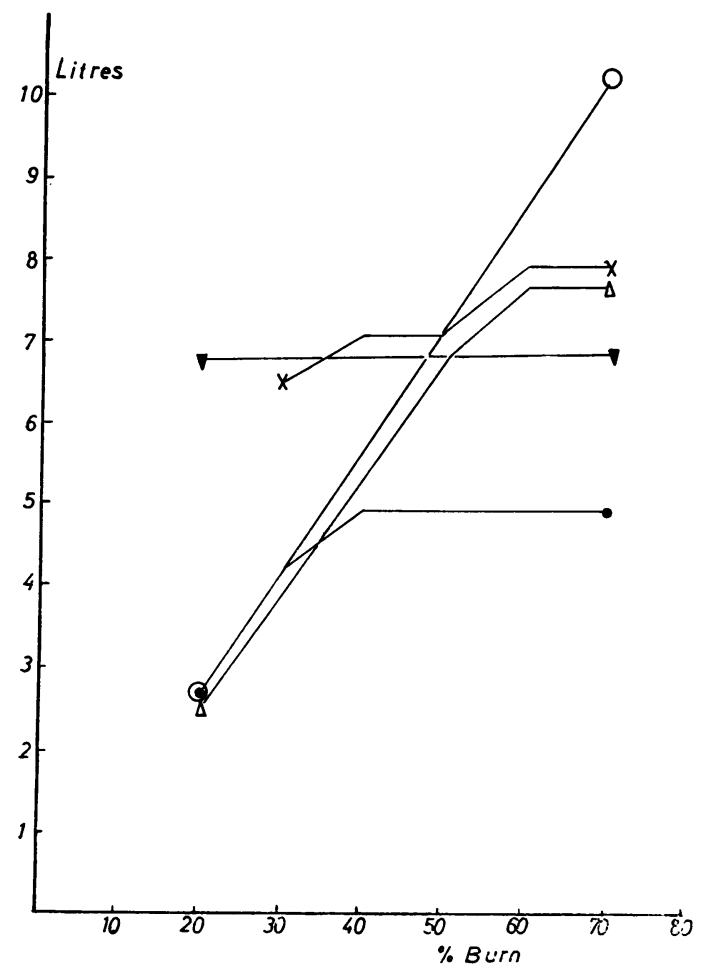

O Harkins (N.R.C., I943)-(half plasma, half saline).

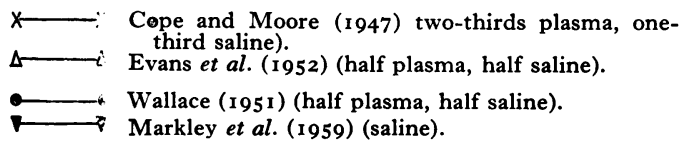

FIG. 2.-Comparison of alternative formulæ for fluid replacement. Quantity of colloid + saline solution recommended for the first 24 hours for burns of various areas in an adult ( $70 \mathrm{~kg}$.).

suggests the need for more colloid infusion to maintain circulatory volume than would be given by the formulæ summarized above. Muir and Barclay (1963) who recommend a combination of a formula and clinical control also agree that larger quantities are often needed.

A separate line of reasoning based on Rosenthal's experiments with mice has led to the suggestion that all the replacement fluid could be saline solution. This was tested in a clinical trial in Peru, and quite good results were reported (Markley, Bocanegra, Bazan, Temple, Chiappori, Morales and Carrion, 1959). However, the colloid therapy with which the saline treatment was compared was inadequate in comparison with the recommended formulæ. The amount of saline recommended was $10 \%$ body weight in 24 hours and a further half of this amount in the next 24 hours (Fig. 2). It is interesting that this total saline corresponds quite closely to the recom- mended volumes of colloid + saline in several of the formulæ, in particular that of Cope. Recento studies have confirmed that such saline therapye is reasonably satisfactory at least for burns up to $30 \%$ surface area. Measurements of circulatorys? volume show that plasma volume is not fullye maintained by this therapy (Davies, 1963) but it음 appears that the low plasma volume is often wells? tolerated when the extracellular volume has been $\mathbb{}$ expanded by the saline solution. Most authoritieso continue to prefer to give some colloid, either, plasma or dextran; Artz, for instance, recommends. a mixture of one part of colloid to three parts of $\vec{\omega}$ saline and total volumes the same as in the Evanso formula (Artz and Reiss, 1957). In emergencyo situations saline therapy only would seem more 3 . promising than might previously have been $\omega_{\oplus}^{\omega}$ suspected.

Apart from the loss of plasma, red cells also areo damaged and destroyed. In burns of less than $\checkmark$ $20 \%$ surface area, the loss during the first two $v$ days is usually less than $10 \%$ of the total red cello volume. This will not normally require specific $\overrightarrow{-}$ blood transfusion, but it should be borne in mind

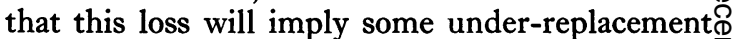
of circulatory volume if the normal hæmatocrit is 3 used as a guide. Burns between 20 and $40 \%$ often $\frac{\Phi}{-}$

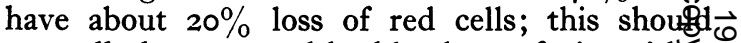
normally be corrected by blood transfusion either. during or at the end of shock therapy. Burns of $40 \%$ surface area or more have a variable red cell loss, usually more than $20 \%$ and sometimes up to as much as $70 \%$ of the circulating red cello volume (Jackson, I959). The amount of whole $\frac{0}{\mathrm{O}}$ skin loss is probably the most important deter- $\varrho$ mining feature in the loss of red cells.

\section{Local therapy}

In the first instance the prevention of infection is the main aim. Recent burns seldom carry을 pathogenic organisms; but the damaged surface is an admirable culture medium. It is therefore 3 . rational to prevent access of organisms to this area by treating the patient in aseptic surroundings $\frac{0}{3}$ (e.g., a plenum ventilated dressing station supplied with filtered air). A no-touch technique and application of prophylactic antibiotic cream, 음 covered with gauze and a generous dressing which extends several inches beyond the edge of $N$ the burn and which includes a layer of dry cotton $N$ wool under a crepe bandage, will further assist N in preventing infection (Colebrook and Hood, $\sigma$ 1948). This type of closed dressing can give satisfactory cover if the burn does not involve $\stackrel{0}{\circ}$ areas such as the face and the perineum, where it $\stackrel{D}{\rightarrow}$ is not feasible to achieve a seal against bacterial ${ }_{0}^{+}$ invasion. Many extensive burns do include such ${ }_{0}^{\circ}$ areas, and in these burns there is the further $\overrightarrow{\mathbb{D}}$ 
difficulty that a dressing which covers the area efficiently also seriously limits heat loss. A compromise must therefore be reached with large burns, though good closed dressings are probably still the treatment of choice for burns limited to limbs or areas of trunk where complete cover can be achieved.

When burns are exposed to the air they develop a dry crust which is relatively resistant to penetration by organisms, and the dry surface is particularly effective in limiting the growth of $P$. pyocyanea. Treatment in this way is probably the method of choice for areas such as the face, buttocks and perineum which, by the above definitions, cannot be treated with dressings giving perfect cover. The limitation of infection by exposure is often, however, more apparent than real (Lowbury, Crockett and Jackson, I954); infection under the dry scab can be very severe and the scab is always liable to cracking which will permit organisms to enter. Exposure treatment, however, is probably preferable to poorly applied 'closed' dressings and there is a further case for its use in high ambient temperatures such as in the tropics, where hyperpyrexia may be a serious danger.

If infection occurs, and it is still all too common in deep burns of large area, it is important to investigate what organisms are present and to provide appropriate therapy (Lowbury, r960). Streptococcal infection is usually amenable to treatment with methicillin, erythromycin or tetracycline. Staphylococci often show some resistance to the common antibiotics, and it is important to establish the most suitable therapy for a particular case. Present experience, however, suggests that resistance to vancomycin and methicillin is likely to be rare. Infection with Pseudomonas pyocyanea can often be controlled with local applications of polymyxin; systemic infections however are very difficult to treat-the polymyxins (including colistin) are the most promising agents.

The aim in prevention and treatment of infection is to minimize the general disturbance due to the injury and to give the best possible prospects of healing. Healing, however, depends also on the depth of the burn and its diagnosis, though clinically so important, is notoriously difficult. Direct inspection can often give little help since surface appearances relate only to the outer layers and give little information on the state of the important deeper layers. The pinprick test for analgesia is often useful (Bull and Lennard-Jones, 1949; Jackson, 1953). If a burn is pricked repeatedly with a sterile hypodermic needle and some pain sensation is present the area can be taken to be partial thickness loss. If analgesia is present, the burn is probably either full thickness or very deep partial thickness loss, though analgesia may be found in areas of thick skin such as the palms and soles and after chemicals such as carbolic acid, yet these burns may heal spontaneously. The test therefore needs careful interpretation but is often useful in permitting recognition of partial thickness areas. Another technique has been recommended by Tempest (196r) by which areas of full thickness burning are demarcated after intravenous injection of dye, though this method has the disadvantage of temporarily staining the normal surrounding skin.

Permanent healing of areas of full thickness burning more than about $3 \mathrm{~cm}$. in diameter cannot be expected within six weeks or more. For all such areas the best treatment is by grafts of skin from elsewhere in the same patient. It is usually convenient to use split skin grafts which leave behind sufficient of the germinal epithelium on the donor site for it to heal spontaneously and take with them sufficient dermis to form a graft of good texture. The optimum time for such grafting is often about ro to 18 days after injury, when the areas which will heal spontaneously have already defined themselves and the remaining full thickness areas can be grafted with the least risk of further complications.

Where it is clear that a small burn is entirely full thickness, the best treatment will probably be to excise the burn on admission, followed immediately by split skin grafting. This gives excellent results in molten metal and other industrial burns of the hands and feet (Ross, 1950; London, 1953). Such treatment saves the period of waiting before grafting and once the graft is applied there is no longer any 'open wound' to serve as an avenue for infection or for loss of exudate. Tentative clinical trials for applying the same principle to larger areas have encountered difficulties, chiefly concerned with the 'take' of the grafts applied after large excisions. The method is therefore not at present generally recommended for areas greater than $10 \%$ of the body surface (Jackson, Topley, Cason and Lowbury, 1960).

In the present state of knowledge only autografts can be relied upon to provide permanent cover, though there has been much investigation into the possibility of using homografts. Even the relatively short survival of a homograft (about 17 days) may be very valuable when very large burns are being treated. For instance, the whole available autograft donor area may be exhausted in covering perhaps half of the full thickness loss. If homograft skin can be put on the remaining half it will last until the donor area is ready for a further crop of autografts to be taken. Another useful technique 
where large flat areas have to be covered, such as the back of the trunk, is to use alternate strips of auto- and homograft so that as the homograft is shed its place can be taken by outgrowth from the adjoining autograft (Jackson, 1954).

For certain special areas such as the face and part of the hands, the use of full thickness grafts may be advisable as a primary operation, in accordance with the usual principles of plastic surgery. Many large burns will also need further operations when contracture later develops in grafted areas. The planning of the total grafting procedure therefore requires great foresight to obtain initial healing as soon as possible and later to obtain full and early function.

\section{General Management}

In practice, patients with serious burns fall into three groups: the first, those with burns greater than $15 \%$ surface area (or $10 \%$ in children) which require fluid replacement. The second group includes other burns sufficiently large or of such areas to require in-patient treatment but not of such a size as to need special fluid replacement; the main aim with these patients is to obtain healing as early as possible, whether by spontaneous regeneration of the skin or by grafting. Burns of the first group present these same problems after the 'shock stage'. The third group consists of the small full thickness burns which are suitable for immediate excision and grafting; once the operation is completed these patients present few further problems.

Most burns sufficiently serious to require hospital treatment cause appreciable disturbance of the general metabolism. Apart from the disorders directly caused by the loss of fluid frow the damaged capillaries, there is a phase greatly increased protein breakdown 3 to 8 days after injury which sooner or later needs correctiơ by extra protein input. It is usually possible start giving a fairly high protein diet within a fe days of even the severest injury. It is disputeg whether much benefit comes from very early ext protein feeding, but it is agreed that extra protein is needed as soon as the period of high protein breakdown ends. Since in a particular patient it is not easy to know the exact timing of this, it reasonable to start high protein intake by about the end of the first week.

Apart from metabolic and other physical upset the burned patient often has to face the discomfon and inconvenience of repeated operations, and may well suffer permanent disfigurement even with the best possible treatment. This may have' serious psychological repercussions, particularly in young children. It seems particularly valuable for burned children under five years of age to bo visited regularly by their mothers, who should be encouraged to assist the nurses in caring for them when this can be arranged the subsequert emotional disturbances are considerably redueg (Woodward, I962).

Burns cause much pain and disability and many deaths, even with the best available treatmen Prevention by modification of our household and industrial habits would seem much the best lor term solution.

\section{REFERENCES}

Arturson, G. (1961): Pathophysiological Aspects of the Burn Syndrome, Acta chir. scand., Suppl. 274.

ARTz, C. P., and Reiss, E. (1957): 'The Treatment of Burns'. London: Saunders.

Bull, J. P. (1961): The Problem of Domestic Burning Accidents, F. roy. Inst. publ. Hlth, $24,11$.

- and LENNARD-Jones, J. E. (1949): The Impairment of Sensation in Burns and its Clinical Application as a Test of the Depth of Skin Loss, Clin. Sci., 8, 155 .

Colebrook, L., and Hood, A. M. (1948): Infection Through Soaked Dressings, Lancet, ii, 682.

CoPe, O., and Moore, F. D. (1947): The Redistribution of Body Water and Fluid Therapy of the Burned Patieñ, Ann. Surg., 128, 1041.

Davies, J. W. L. (1960): A Critical Evaluation of Red Cell and Plasma Volume Techniques in Patients with Burns, F. clin. Path., 13, 105.

be published.

Evans, E. I., Purnell, O. J., Robinett, P. W., Batchelor, A., and Martin, M. (1952): Fluid and Electrolyte Require: ments in Severe Burns, Ann. Surg., 135, 804.

HARKINS (1943): in Burns, Shock, Wound Healing and Vascular Injuries. National Research Council. Philadelphïaj Saunders.

Jackson, D. M. (1953): The Diagnosis of the Depth of Burning, Brit. F. Surg., 40, 588.

(1954): A Clinical Study of the Use of Skin Homografts for Burns, Brit. $\mathcal{Y}$. plast. Surg., 7, 26.

(1959): Diagnosis in the Management of Burns, Brit. më̈. Y., i, 1263. , Topley, E., Cason, J. S., and LowBury, E. J. L. (1960): Primary Excision and Grafting of Large Burns, Anê Surg., 152, 167.

London, P. S. (1953): The Burnt Foot, Brit. F. Surg.; 40, 19.

Lowbury, E. J. L. (1960): Infection of Burns, Brit. med. $\mathcal{J} .$, i, 994.

- Crockett, D. J., and Jackson, D. M. (1954):-Bacteriology of Burns Treated by Exposure, Lancet, ii, 1151. 
Markley, K., Bocanegra, M., Bazan, A., Temple, R., Chiappori, M., Morales, G., and Carrion, A. (r959): Clinical Evaluation of Saline Solution Therapy in Burn Shock, F. Amer. med. Ass., 170, 1633.

Moritz, A. R., and Henriques, F. C. (1947): Studies of Thermal Injury: II. The Relative Importance of Time and Surface Temperature in the Causation of Cutaneous Burns, Amer. F. Path., 23, 695.

MuIR, I. F. K., and BARCLAY, T. L. (1962): 'Burns and their Treatment'. London: Lloyd-Luke.

Ross, W. P. D. (1950): The Treatment of Recent Burns of the Hand, Brit. F. plast. Surg., 2, 233.

Sevitt, S. (1949): Local Blood Flow Changes in Experimental Burns, F. Path. Bact., 6r, 427.

(1956): Distal Tubular and Proximal Tubular Necrosis in the Kidneys of Burned Patients, f. clin. Path., 9, 279.

Tempest, M. N. (1961): A New Technique in the Clinical Assessment of Burns, Trans. Ass. industr. med. Offrs, II, 22.

Topley, E., and Jackson, D. M. (1957): The Clinical Control of Red Cell Loss in Burns, f. clin. Path., ro, I. , Bull, J. P., Maycock, W. D'A., Mourant, A. E., and Parkin, D. (1963): The Relation of the Isoagglutinins in Pooled Plasma to the Hæmolytic Anæmia of Burns, Ibid., 16, 79.

Wallace, A. B. (195I): The Exposure Treatment of Burns, Lancet, i, 501 .

Woodward, J. (1962): Parental Visiting of Children with Burns, Brit. med. F., ii, r656. 